\title{
Nanoquímica: Ingeniería de Nanomateriales
}

\author{
GABRIEL Alonso-NúÑ̃Z*
}

$E_{m}^{n}$ la ingeniería de nanomateriales es muy importante conocer las condiciones óptimas para llevar a cabo una reacción química que permita obtener un producto con propiedades interesantes. Para lograr este objetivo, se debe entender la química a nivel molecular. En este trabajo se describen algunos métodos químicos, los cuales nos permiten obtener materiales nanoestructurados y se dan algunos ejemplos de sus aplicaciones. Explicaremos sobre la preparación de nanotubos de carbón de multipared mediante una técnica conocida como "spray pyrolysis", así como también sobre la síntesis de nanopartículas depositadas en dichos nanotubos, la cual se lleva a cabo por el método de microemulsión.

\section{INTRODUCCIÓN}

$\mathbf{U}$ n área de investigación de mucha actualidad es el desarrollo de auto-ensambles nanoestructurados para fabricar nuevos materiales. Se espera que dichos materiales posean propiedades únicas, las cuales los hagan útiles en áreas como la electrónica, la medicina, la catálisis, los cosméticos, los alimentos, etc. Se sabe que al reducir el tamaño de los materiales a escala nanométrica, éstos adquieren propiedades diferentes en relación con su tamaño macroscópico (partículas micrométricas). Así, por ejemplo, las nanoestructuras presentan mayor área superficial, mayor reactividad química y selectividad, son más ligeras y presentan propiedades electrónicas y ópticas que dependen de su tamaño en esta escala. Las nanoestructuras pueden tener cero, una o dos dimensiones (0D, 1D y 2D respectivamente). En el primer caso, se conocen como puntos cuánticos y un ejemplo de ello son las nanopartículas. Los nanoalambres y nanotubos son nanoestrucutras de 1D, mientras que los recubrimientos de capas delgadas son nanoestructuras de 2D (Iijima, 1991).La nanoquímica es una herramienta que permite desarrollar materiales complejos o sistemas autoensamblados a escala molecular. Durante los últimos años, la química ha evolucionado hacia un modelo multidisciplinario, el cual ha llevado a la fusión de la química orgánica, inorgánica, la fisicoquímica, bioquímica y los polímeros como disciplinas emergentes englobadas dentro del término nanociencia y nanotecnología. Mientras que la nanociencia es el conjunto de conocimientos y metodologías dirigidos a estudiar, sintetizar y caracterizar los materiales nanoestructurados. La nanotecnología se define como el desarrollo que permite la construcción y manipulación de materiales a escala nanométrica. Todo esto promete un impacto social y económico mayor en varios órdenes de magnitud que el logrado por las tecnologías que existen hasta la fecha.

* Centro de Nanociencias y Nanotecnología-UnAM; Centro de Investigación en Materiales Avanzados S.C., Miguel de Cervantes 120, Complejo Industrial Chihuahua, C.P. 31109, Chihuahua, México. Contacto: galonso@cnyn.unam.mx 


\section{LOS NANOTUBOS DE CARBÓN}

La investigación en nanotubos de carbono (1D) ha despertado gran interés científico (Rothschild et al., 2000). Éstos consisten en estructuras tubulares o cilindros de hojas de grafito. A los nanotubos de carbono (NTC) de una sola hoja se les llama nanotubos de carbono de pared simple (Figura 1a), mientras que cuando éstos están formados por más de dos hojas, se les denomina NTC de multipared (Figura 1b).

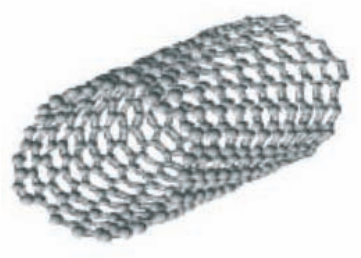

(a)

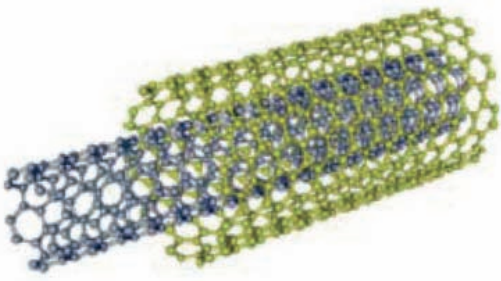

(b)

FIGURA 1. NTC a) de una sola pared (sWCNT), b) de multipared (MWCNT).

Los NTC poseen varias propiedades superiores a otros materiales, por ejemplo: su resistencia a la tracción es de $45 \times 10^{9}$ pascales mientras que la del acero es de $2 \times 10^{9}$ pascales su capacidad de corriente se estima de $1 \times 10^{9}$ $\mathrm{A} / \mathrm{cm}^{2}$, mientras los hilos de cobre se funden a $1 \times 10^{6} \mathrm{~A} / \mathrm{cm}^{2}$. Debido a las

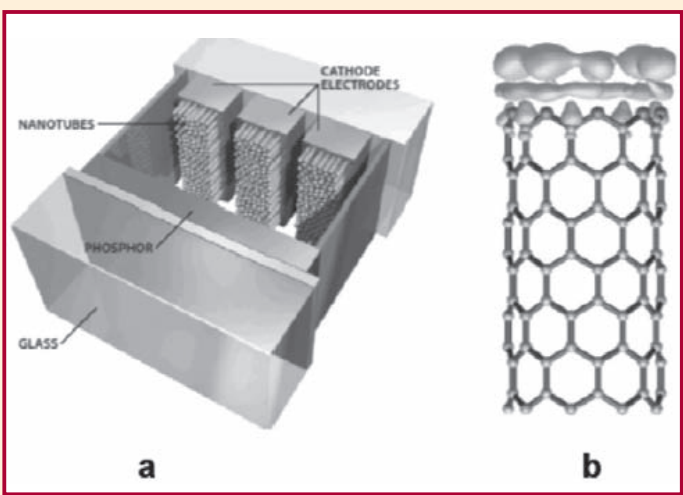

FIGURA 2. a) Esquema de una pantalla de tv utilizando CNT; b) NTC dopados con B, los cuales podrían incrementar el efecto

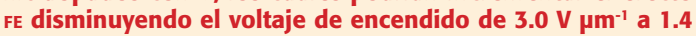
$\mathbf{V} \mathbf{m}^{-1}$. propiedades electrónicas únicas de los nanotubos de carbono, éstos pueden ser usados como materiales de emisión de campo o "field-emission" (FE). Ésta es la capacidad de algunos materiales de emitir electrones bajo un intenso campo eléctrico. Una de las aplicaciones relacionadas con este efecto es la de su uso en las FED (fiel emission display) de las nuevas pantallas planas de TV (Figura 2) (Seraphin, 2006). El efecto FE también permite usar los NTC como puntas emisoras de electrones en los microscopios electrónicos de barrido y en los microscopios de fuerza atómica.

\section{MÉTODOS DE FABRICACIÓN}

La síntesis de NTC de multipared se lleva a cabo mediante el método de "spray pyrolysis" (Aguilar- 
Elguézabal et al., 2006). Se tiene un tubo "vicor" (óxido de silicio o vidrio), el cual se calienta a $900^{\circ} \mathrm{C}$ dentro de un horno cilíndrico equipado con un controlador de temperatura. Una solución de $25 \mathrm{~mL}$ preparada con ferroceno y tolueno se alimenta por medio de un nebulizador con un flujo de Argon al interior del tubo "vicor". En el interior de este tubo, las moléculas de tolueno se descomponen en átomos de carbono y se ordenan hexagonalmente en forma de nanotubos. Esto sucede por la presencia de nanopartículas de hierro provenientes de la descomposición del ferroceno, las cuales funcionan como catalizadora de la formación de los NTC. De esta manera, se deposita una capa de NTC en forma radial con respecto a la pared interior del tubo "vicor".

En la figura 3a y 3b se muestran las imágenes de microscopía electrónica de barrido de los NTC obtenidas a baja y alta amplificación respectivamente. En la figura 3a se observa el crecimiento de NTC tipo bosque, éstos se encuentran alineados verticalmente sobre un trozo de tubo "vicor". Una micrografía de alta resolución con un microscopio electrónico de transmi-
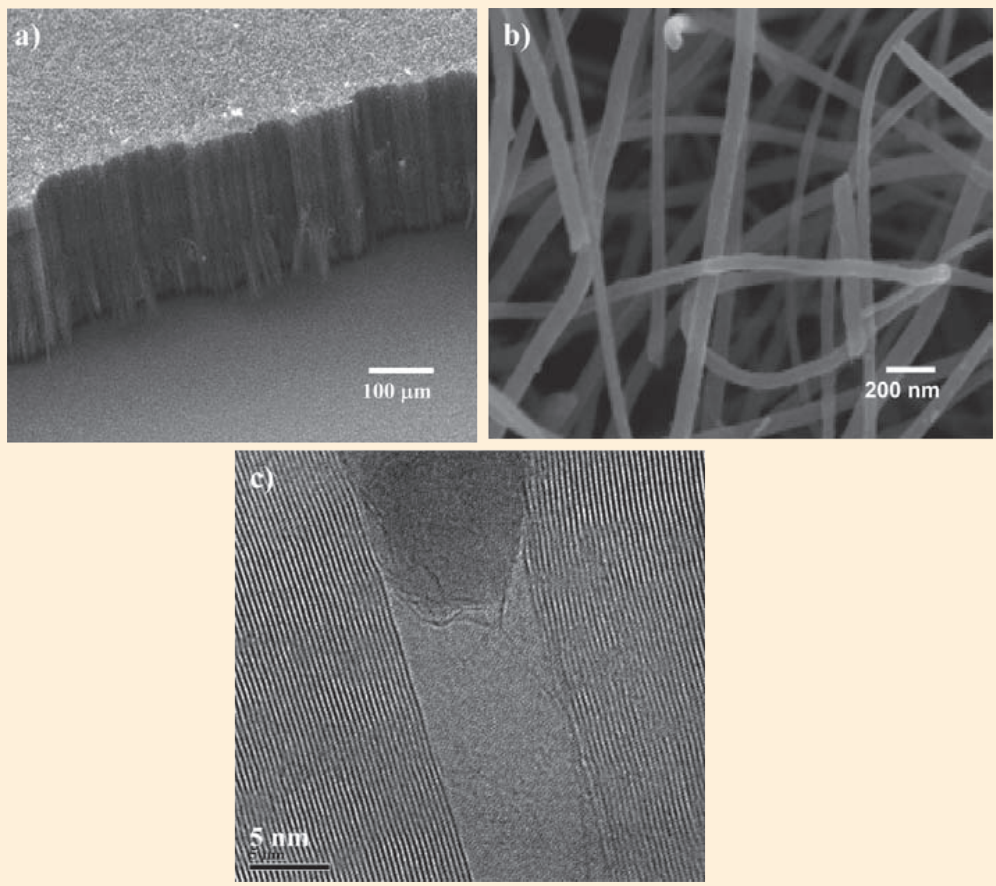

FIGURA 3. Imágenes de NTC de multipared. a) Crecimiento de los NTC sobre tubo "vicor", b) Amplificación de NTC. c) Imagen de alta resolución donde se muestran las paredes de carbono de un nanotubo. 
sión se muestra en la figura 3c donde se pueden observar claramente las paredes de carbono de un nanotubo de multipared.

El depósito de nanopartículas sobre los nanotubos de carbono se lleva a cabo por el método de microemulsión. En las siguientes líneas, daremos una breve explicación acerca de este proceso. Existen diferentes tipos de microemulsiones. Por ejemplo: la de agua en aceite (w/o) se forma cuando una pequeña cantidad de agua se dispersa en una fase continua de algún hidrocarburo con la ayuda de un surfactante. La relación molar agua/surfactante tiene un valor específico en el cual permite la formación de micelas ("gotas") invertidas. Éstas actúan como nanorreactores donde se llevan a cabo las reacciones químicas de forma muy controlada. Estas micelas son de tamaño menor a los $10 \mathrm{~nm}$. Los surfactantes son macromoléculas que presentan una parte hidrofóbica (afinidad al aceite o al hidrocarburo) y otra parte hidrofílica (afinidad por el agua). La parte hidrofóbica está constituida por una o varias cadenas de hidrocarburo. La parte hidrofílica está formada por un grupo frontal, el cual es polar o iónico donde interaccionan los precursores metálicos que darán lugar a las nanopartículas. Las propiedades de los surfactantes son esenciales para la construcción de máquinas moleculares que tengan propiedades tales como auto-organización, ensamblaje, autorreproducción y reconocimiento. Las microemulsiones son sistemas líquidos homogéneos a escala macroscópica, pero son heterogéneos en la escala molecular, ya que existen dominios de agua y aceite separados por una monocapa de surfactante. El tamaño típico de estos dominios está por debajo de la longitud de onda de la luz visible, por lo que estos sistemas son óptimamente transparentes. Este método consiste básicamente en aislar y confinar los precursores de las nanopartículas en una de las fases del sistema, con el fin de facilitar los procesos específicos de reacción y difusión.

La frontera entre el medio y la región de confinamiento está constituida por los surfactantes, los cuales delimitarán el espacio requerido para la formación de la nanopartícula. Una vez sintetizada la nanopartícula (reducción del catión metálico), dichos surfactantes quedan absorbidos a la superficie de las mismas previniendo la aglomeración y precipitación de éstas. Al mismo tiempo, permiten tener un control del tamaño y la forma de la nanopartícula. Los NTC funcionan como soporte de las nanopartículas, para lograr mayor dispersión de éstas y así aumentar el área superficial. Además, los soportes con base en carbono presentan gran interés debido a características específicas como son: su resistencia a los medios ácido/base y por su transporte electrónico (Verde et al., 2007). Las nanopartículas sintetizadas por microemulsión y soportadas en NTC presentan propiedades útiles en catálisis heterogénea, por ejemplo: como electroca- 
talizadores en celdas de combustible de intercambio protónico, síntesis de metanol, producción de hidrógeno, fotocatálisis, oxidación de olefinas e hidrocarburos y foto-electrólisis del agua (Eriksson, 2004).

Aquí se describe la síntesis de nanopartículas de Ru y Pt depositadas sobre NTC por el método de microemulsión. Primero se prepara una solución acuosa de hexaclororutenato de amonio $\left(\mathrm{NH}_{4}\right)_{2} \mathrm{RuCl}_{6} \mathrm{o}$ ácido hexacloroplatínico $\mathrm{H}_{2} \mathrm{PtCl}_{6}$ como precursores de nanopartículas de $\mathrm{Ru}$ o Pt respectivamente a una concentración de $0.01 \mathrm{M}$. Como surfactante se utilizó el éter-docecil-glicol-tetraetileno y hexano como fase oléica, posteriormente se añadió una suspensión CNT previamente dispersados en la misma fase oléica. Todo el proceso se realiza en constante agitación con la finalidad de depositar las micelas sobre la superficie de los nanotubos aprovechando su carácter hidrofóbico. Finalmente, las nanopartículas depositadas sobre los NTC se obtienen al precipitar el material con acetona y una solución de agente reductor (borohidruro de sodio) sobre la suspensión. El material se filtra y se seca.

En la figura 4 se muestran las imágenes por microscopía electrónica de transmisión de las nanopartículas de Ru depositadas sobre NTC por el método de microemulsión. En la figura 4a se observan las nanopartículas de Ru de aproximadamente $7 \mathrm{~nm}$ de diámetro sobre los NTC de multipared. En la figura $4 \mathrm{~b}$ se observa la distribución homogénea de nanopartículas de $\mathrm{Ru}$ a lo largo de un nanotubo de carbono con un histograma indicando el promedio del tamaño de las nanopartículas.

Por este mismo método de síntesis se pueden obtener materiales bimetálicos. En la figura 5 se muestran las imágenes de nanopartículas de Pt-Ru a baja (a) y alta (b) amplificación y soportadas en NTc. En la imagen
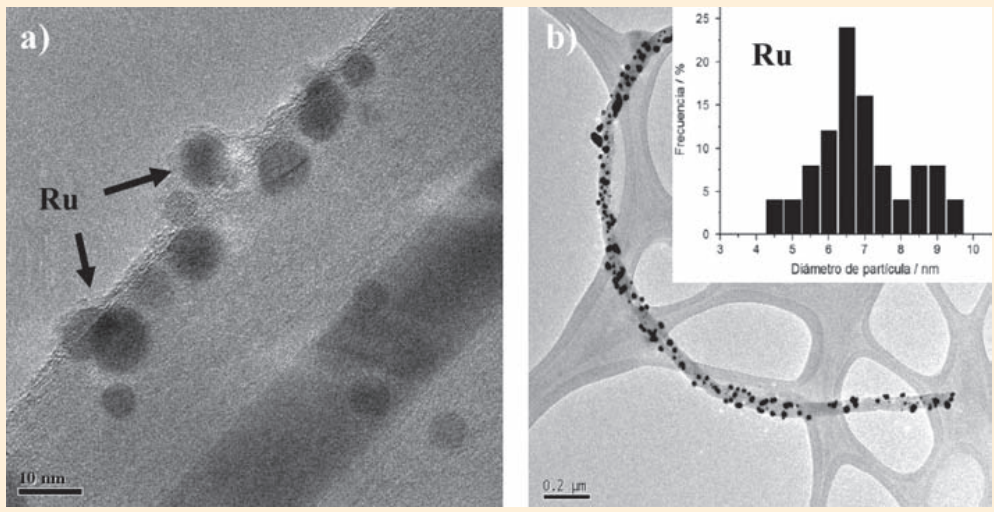

FIGURA 4. Nanopartículas de Ru depositadas en NTC. a) Amplificación de las nanopartículas de Ru. b) Histograma de distribución de nanopartículas de Ru. 

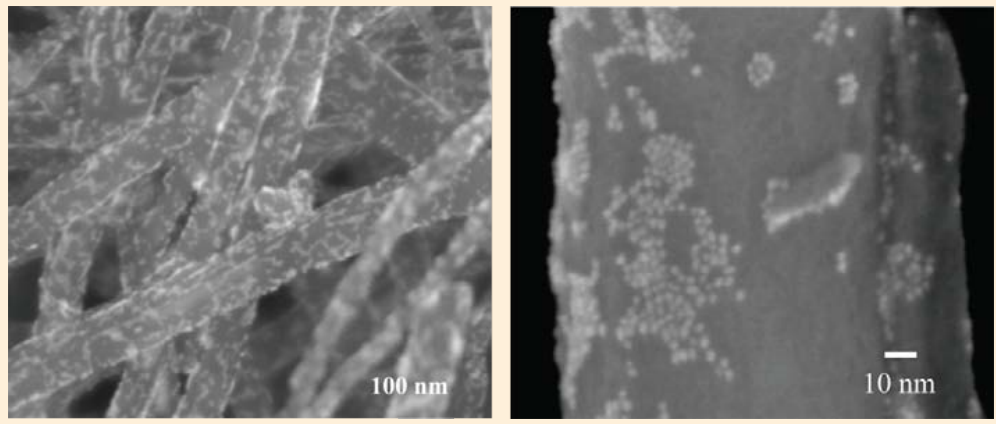

FIGURA 5. Nanopartículas de Ru-Pt soportadas en NTC. a) baja y b) alta amplificación.

5b se puede observar que las nanopartículas presentan una dispersión y un diámetro homogéneo de $4 \mathrm{~nm}$ aproximadamente.

\section{Conclusiones}

Por el método de spray pyrolysis se obtienen NTC de multipared con buena calidad, siendo éste, un proceso sencillo y de bajo costo. Por el método de microemulsión se logra obtener nanopartículas de tamaño homogéneo y depositadas con buena dispersión sobre NTC.

\section{BiBLIOGRAFÍA}

Iijima, S., (1991). "Helical microtubules of graphitic carbon." Nature 354, 56-58. Rothschild, A., Sloan, J. y Tenne, R., (2000). "Growth of WS 2 Nanotubes Phases”. Journal of the American Chemical. Society. 122, 21: 5169.

Seraphin, S., (2006). "Brief Review: Basic Properties and Applications of Carbon nanotubes". Microscopy Today. Vol 14, No. 2.

Aguilar-Elguézabal, A., Antunez, W., Alonso, G., Paraguay, F., Espinosa, F., Mikiyoshida, M. (2006). Diamond and Related Materials. Vol. 15, No. 9: 1329-1335.

Verde, Y., Leer, A., Miki Yoshida, M., Paraguay-Delgado, F., Alonso-Nuñez, G., Avalos, M., (2007). "Aqueous Deposition of Metals on Multiwalled Carbon Nanotubes to be used as Electrocatalyst for Polymer Exchange Membrane Fuel Cells". Journal of fuel cell science and technology. Vol. 4, No. 2.

Eriksson et al., (2004). "Preparation of catalysts from microemulsions and their applications in heterogeneous catalysis". Applied Catalysis A: General. Vol. 265, No.2: 207. 